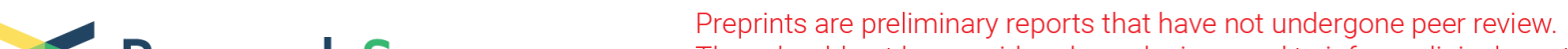 $\begin{array}{ll}\text { Research Square } & \text { They should not be considered conclusive, used to inform clinical practice, } \\ \text { or referenced by the media as validated information. }\end{array}$
}

\section{Risk factors associated with the detection of pulmonary emphysema in older asymptomatic respiratory subjects}

Ivette Buendia-Roldan ( $\sim$ ivettebu@yahoo.com.mx )

Instituto Nacional de Enfermedades Respiratorias https://orcid.org/0000-0002-2825-506X

Alexia Palma-Lopez

Instituto Nacional de Enfermedades Respiratorias y del Ambiente

Danaireth Chan-Padilla

Instituto Nacional de Enfermedades Respiratorias

lliana Herrera

Instituto Nacional de Enfermedades Respiratorias

Mariel Maldonado

Instituto Nacional de Enfermedades Respiratorias

Rosario Fernandez-Plata

Instituto Nacional de Enfermedades Respiratorias

David Martinez-Briseño

Instituto Nacional de Enfermedades Respiratorias

Mayra Mejia

Instituto Nacional de Enfermedades Respiratorias

Moises Selman

Instituto Nacional de Enfermedades Respiratorias

Research article

Keywords: Aging, pulmonary emphysema, COPD, risk factors, Klotho, telomere length.

Posted Date: March 11th, 2020

DOI: https://doi.org/10.21203/rs.3.rs-16801/v1

License: (c) (i) This work is licensed under a Creative Commons Attribution 4.0 International License. Read Full License

Version of Record: A version of this preprint was published at BMC Pulmonary Medicine on June 9th, 2020. See the published version at https://doi.org/10.1186/s12890-020-01204-9. 


\section{Abstract}

Background: Several lung structural and functional abnormalities may occur associated withaging, including emphysema. In this study, we evaluated the frequency and risk factors associated with emphysema in respiratory asymptomatic individuals enrolled in our Lung Aging Program. From a cohort of 687 subjects, we found by high-resolution computed tomography (HRCT) 29 individuals (4\%) withemphysematous changes that were compared with 87 controls (3:1) randomly selected from the same cohort. Methods: This was atransversal, observational, case-control study where we examined demographics and functional characteristics, as well as telomere length and serum Klotho concentration, two conditions that have been associated with aging and some aging-associated diseases including emphysema. Results: Individuals with subclinical pulmonary emphysema were older (72 \pm 9 versus $67 \pm$ 6 years), and primarily smoker males with low body mass index. Despite that they were asymptomatic, two of them exhibited a decrease of forced expiratory volume in 1 second (FEV 1 ), with a lower FEV 1 /FVC suggesting airway obstruction. Cigarette smoking (OR=5.43, Cl95\% 1.8-16.7), family history of lung disease $(\mathrm{OR}=4.32, \mathrm{Cl} 95 \%$ 1.0-19.0) and lower body mass index (OR 7.22, Cl95\% 1.2-3.5) were risk factors for the development of lung emphysematous changes. No association was found with telomere length and Klotho serum concentration. Conclusion: Our findings reveal that a small but important percentage of olderpeople without respiratory symptoms, present pulmonary emphysema and indicate that smoking exposure and genetic background may contribute as etiological factors.

\section{Introduction}

Aging is a normal biological process associated with multiple anatomic and functional abnormalities and morbidities. The physiological effects of aging in the lungs include, among others, a progressive decrease in forced vital capacity with an increase of pulmonary vascular resistance (1). The lungs of older people may also show interstitial lung abnormalities, decreased elastic recoil and decreased diameter of the small airways with premature close of the peripheral airways (2).

Some individuals develop changes in the lung structure with an increase in the size of the alveolar spaces (over-distension) without inflammation or alveolar wall destruction, so-called "senile emphysema" a term that has been discarded (3). By contrast, some individuals mostly smokers may develop "real" emphysema characterized by alterations of the extracellular matrix, destruction of the alveolar walls and loss of the lung architecture $(3,4)$. These changes are usually, but not always associated with airways alterations constituting the chronic obstructive pulmonary disease (COPD).

The presence of emphysema as the only alteration is uncommon and has been mainly associated with alpha-1-antitrypsin deficiency (5). However, the frequency and pathogenic mechanisms of emphysema in asymptomatic older individuals without a known genetic etiology remains uncertain.

In the last years, we have been working on a "Lung Aging Program" involving respiratory asymptomatic individuals $\geq 60$ years, both smokers and non-smokers, who have lived in Mexico City at least during the 
last 10 years (altitude $\sim 2500 \mathrm{mts}$ over sea level).

In this cohort, we found by high-resolution computed tomography (HRCT) $4 \%$ of individuals with emphysematous changes affecting $\geq 5 \%$ of the lung parenchyma. In this context, the aim of our study was to evaluate demographics and functional characteristics, as well as telomere length and serum Klotho concentration in individuals with subclinical pulmonary emphysema compared with controls randomly selected from the same cohort to identify risk factors to develop this disease. The length of telomeres and levels of Klotho were selected because telomere dysfunction and marked decrease of circulating Klotho have been associated with $\operatorname{COPD}(6,7)$.

\section{Methods}

\section{Study Population}

Our Aging Lung Program voluntarily enrolls respiratory asymptomatic individuals over 60 years that have been living in Mexico City for at least 10 years. The cohort includes current, former and non-smoker subjects. Individuals with body mass index $\left(\mathrm{BMI}, \mathrm{kg} / \mathrm{m}^{2}\right)$ lower than 18.5 and obese $(\mathrm{BMI}>30)$ are excluded.

Several questionnaires are applied to evaluate demographic, and health and respiratory status, including PLATINO, a composite instrument that has sections of ATS/DLD, ECRHS II, Lung Health Study, and SF-12 (8),

All individuals perform pulmonary function tests including forced vital capacity (FVC), forced expiratory volume in 1 second $\left(\mathrm{FEV}_{1}\right)$, diffusing capacity of the lung for carbon monoxide $\left(\mathrm{DL}_{\mathrm{CO}} \%\right)$ corrected for altitude, and six-minutes' walk test where changes in oxygen saturation and walked distance are measured.

In the same day, individuals underwent high resolution computed tomography (HRCT) helicoidal scanning (Somatom, definition AS 128 detectors double-energy, Siemens), in supine and prone position and the interpretation of images is performed by two pulmonologists and one radiologist with at least 10 years of experience.

From our current cohort of 687 respiratory asymptomatic individuals, 29 showed HRCT image features of pulmonary emphysema (Fig. 1). These individuals were compared with 87 controls from the same cohort (3:1) randomly selected. Signed informed consent letter was obtained from all participants of the Program, and the study was approved by Research and Ethic Committees of our Institute (C39-14).

\section{Analysis of telomere length by quantitative real-time PCR}

Relative telomere length was measured by quantitative polymerase chain reaction (qPCR) as previously described (11). Genomic DNA was extracted from blood samples and reactions were performed with the 
following reagents: Power SYBR® Green PCR Master Mix (Life Technologies, UK), RNase free water (SIGMA, UK), primer single gene (S) forward (36B4d F-300 nM) (CCCATTCTATCATCAACGGGTACAA) and single copy gene (S) reverse (36B4u R-300 nM) (CAGCAAGTGGGAAGGTGTAATCC), primer Tel (T) Forward (900 nM) (CGGTTTGTTTGGGTTTGGGTTTGGGTTTGGGTTTGGGTT), Tel (T) Reverse (900 nM) (GGCTTGCCTTACCCTTACCCTTACCCTTACCCTTACCC). The cycling profile was: $95^{\circ} \mathrm{C}$ for $10 \mathrm{~min} ; 9^{\circ} \mathrm{C}$ for $15 \mathrm{~s}, 58^{\circ} \mathrm{C}$ for $1 \mathrm{~min}, 72^{\circ} \mathrm{C}$ for $30 \mathrm{~s}$ x 40 cycles; $95^{\circ} \mathrm{C}$ for $15 \mathrm{~s}, 55^{\circ} \mathrm{C}$ for $15 \mathrm{~s}$ and $95^{\circ} \mathrm{C}$ for $15 \mathrm{~s}$. Outlier values were excluded. The relative value for telomere length telomere repeats copies number $(T)$ to a single copy gene (S) (T/S) ratio was determined by comparison with control calibration curves and was graphed as natural logarithm $(\mathrm{LN})$ versus age.

\section{Serum levels of soluble a-Klotho}

a-Klotho was evaluated in serum by enzyme-linked immunosorbent assay (ELISA) using a commercial kit (IBL América, Cat 279988) according to the manufacturer's protocol.

\section{Statistical analysis}

Results were expressed as mean \pm standard deviation. Comparison between groups was performed by Fisher's exact for categorical values and U-Mann Whitney for continuous variables; significance was defined as $P<0.05$. Multivariable logistic regression was used to assess factors associated with emphysema using the program Stata for Windows, version 12.

To obtain the correlation between relative telomere length and age, linear regression was performed using integrated data analysis in GraphPad Prism v6 (GraphPad Software Inc, CA, USA). The natural log transformed relative T/S ratio was normally distributed.

\section{Results}

\section{Demographic characteristics}

Individuals with pulmonary emphysema were older male and primarily former cigarette smokers compared with the non-emphysema control group (Table 1). They also showed a lower body mass index compared with controls. Interestingly, subjects with emphysema had more often history of relatives with some chronic lung disease (Table 1). The type of emphysema was predominantly centrilobular (79\%). Four percent showed pan-lobular emphysema and in $17 \%$ was mixed.

\section{Demography Factors And Co Morbidities}

Table 1

Demography factors and co morbidities 


\begin{tabular}{|llll|}
\hline Variable & $\begin{array}{l}\text { Emphysema } \\
\mathbf{n = 2 9}\end{array}$ & $\begin{array}{l}\text { Control } \\
\mathbf{n = 8 7}\end{array}$ & $\mathbf{p}$ \\
\hline Gender, (male: female) & $22: 7$ & $23: 64$ & $<0.0001$ \\
\hline Chronological age, years (SD) & $72 \pm 9$ & $67 \pm 6$ & 0.004 \\
\hline Body mass index (SD) & $24 \pm 3$ & $27 \pm 4$ & 0.0007 \\
\hline Cigarette smoking, former (\%) & $23(79)$ & $36(41)$ & $<0.0001$ \\
\hline Occupational exposition, (\%) & $15(52)$ & $35(40)$ & 0.279 \\
\hline Family history with lung disease, (\%) * & $5(17)$ & $4(5)$ & 0.02 \\
\hline
\end{tabular}

\section{Pulmonary function tests}

Two of the individuals with emphysema exhibited a decrease of $\mathrm{FEV}_{1}$ ( $45 \%$ and $46 \%$ percent predicted), with a lower $F E V_{1} / F V C$ indicating airway obstruction. These two individuals also showed a lower $\mathrm{DL}_{\mathrm{CO}}$ (66\% and $64 \%$ percent predicted), and one of them displayed oxygen desaturation after exercise. The rest of the subjects have normal spirometry without differences with the control group (Table 2). However, as a group, even removing the two subjects with significant decrease of $\mathrm{DL}_{\mathrm{CO}}$, individuals with emphysema showed a lower $\mathrm{DL}_{\mathrm{CO}}$ but without differences in oxygen saturation and walked distance after exercise (Table 2).

Table 2

Lung function test results

\begin{tabular}{|c|c|c|c|}
\hline & $\begin{array}{l}\text { Emphysema } \\
n=29\end{array}$ & $\begin{array}{l}\text { Control } \\
n=87\end{array}$ & $\mathrm{p}$ \\
\hline FVC, \%predicted, ( \pm SD) & $93 \pm 15$ & $96 \pm 16$ & 0.06 \\
\hline FEV1, \%predicted, ( $($ SD)* & $95 \pm 16$ & $100 \pm 17$ & 0.2 \\
\hline FEV1/FVC \%, ( \pm SD) & $101 \pm 11$ & $104 \pm 8$ & 0.1 \\
\hline $\mathrm{DL}_{\mathrm{CO},} \%$ predicted, $( \pm \mathrm{SD})^{*}$ & $104 \pm 20$ & $115 \pm 20$ & 0.01 \\
\hline Sp02 at rest, \% ( \pm SD) & $94 \pm 2$ & $94 \pm 2$ & 0.7 \\
\hline Meters 6-MWT, $( \pm S D)$ & $91 \pm 6$ & $92 \pm 4$ & 0.3 \\
\hline
\end{tabular}

\section{Leukocyte telomere length}

Since abnormal shortening of telomeres has been associated with COPD (6) we wonder whether telomere length was also associated with the presence of subclinical pulmonary emphysema. However, as shown 
in Fig. 2A, no significant difference between the control and emphysema groups was detected.

\section{Serum concentration of Klotho}

Low levels of soluble Klotho have been also associated to COPD (12). In this context, we evaluated serum Klotho concentrations by ELISA. As shown in Fig. 2B, no significant differences were found between individuals with subclinical pulmonary emphysema $(762.6 \pm 238 \mathrm{pg} / \mathrm{ml})$ and controls $(695.02 \pm$ $287 \mathrm{pg} / \mathrm{ml} ; \mathrm{p}=0.15)$.

\section{Risk factors}

Three risk factors were significantly associated with the presence of emphysema, family history of lung disease [OR 4.32 (CI95\%1.003-19.09)], cigarette smoking [OR 5.43 (CI95\% 1.8-16.7)], and lower body mass index [OR 7.22 (CI95\% 1.2-3.5)] (Fig. 3). Family lung disorders included airways and parenchymal diseases such as chronic obstructive pulmonary disease, chronic bronchitis, emphysema and pulmonary fibrosis. A non-significant tendency was found with the history of environmental and occupational exposure [OR 1.59 (CI95\% 0.63-4.03)].

\section{Discussion}

Pulmonary emphysema represents a form of destruction of the lung architecture characterized by an abnormal and permanent enlargement of the air space distal to the terminal bronchioles, with destruction of the alveolar walls, and without obvious fibrosis (13). Emphysema, usually as part of COPD, represents a slowly progressive and irreversible lung disorder, resulting in respiratory insufficiency and reduction in life expectancy and life quality. Pulmonary emphysema may occur associated with gene mutations such as alpha1-antitrypsin and telomerase components $(14,15)$, but the sporadic form associated with COPD, is primarily related with the exposure to cigarette smoke and other respiratory environmental or occupational exposures such as gases, biomass smoke, fumes and dusts (16).

Unfortunately, the onset and progression of emphysema, COPD and other lung diseases associated with aging is insidious and are often misdiagnosed leading to irreversible damage before diagnosis. Thus, many patients are identified as having 'smoker's cough', asthma or bronchial infection and are diagnosed too late.

Importantly, HRCT represents a consistent diagnostic tool even for subtle modifications in secondary pulmonary lobules, then allowing an early diagnosis. Likewise, pulmonary function tests may help to the early detection of these age-associated disorders. Actually, it has been suggested to perform communitybased spirometry to find patients with early disease, mainly in smoker individuals over 40 years old who present with lower respiratory tract symptoms (17).

However, HRCT screening is more sensitive than lung function tests for emphysema detection, because it may show structural changes even with no airway obstruction (18). Our study corroborates this notion 
because we were able to detect emphysematous changes in the lungs of individuals without airway obstruction.

In our study, we found that from almost 700 individuals evaluated so far, around $4 \%$ of them, without respiratory symptoms, show pulmonary emphysema by HRCT. Only two of them show a significant decrease of $\mathrm{FEV}_{1}$ and $\mathrm{FEV}_{1} / \mathrm{FVC}$ ratio, indicating airway obstruction. Interestingly, even excluding them, individuals with emphysema exhibited decreased $\mathrm{DL}_{\mathrm{CO}}$ suggesting an early alteration in gas exchange (Table 2).

Detecting subclinical emphysema that is lung alterations in the early stages, (e.g., respiratory asymptomatic individuals such as in our study) can help to provide timely preventive interventions and treatment, avoiding long term complications and improving the quality of life of people with chronic respiratory disorders. For example, it has been found that detection of mild emphysema with normal functional pulmonary tests in young smokers led to negative impacts on their quality of life (17).

We were also interested in detect risk factors and putative biomarkers. As expected, the frequency of pulmonary emphysema was higher in cigarette smokers, which has been clearly identified as its major risk factor. However, this disorder was also observed in never smokers indicating that other risk factors are involved, and our results show that family history of lung disorders also influence the risk to develop emphysema suggesting some inherited susceptibility. This finding agrees with studies in large cohorts which indicate that family history of COPD is a strong risk factor for the development of the same disease, independent of personal lifetime smoking, or childhood environmental tobacco smoke exposure $(19,20)$.

Individuals with emphysema were chronological older compared with controls, but interestingly, highest phenotypic age relative to the chronological age also seemed to be associated with emphysema. This is an important observation since it has been previously demonstrated that Phenotypic Age, a novel clinically based measure of aging, was predictive of mortality among both healthy and unhealthy populations even after adjusting for chronological age (9).

We also investigated whether the circulating concentrations of Klotho, an anti-aging molecule, or the leukocyte telomere length are associated with the risk for pulmonary emphysema, but no differences with the control group were detected. These findings suggest that alterations in these two molecules are noticeable in more advance disease.

This study has several limitations. First, the sample size was small and the number of molecular evaluations restricted. Second, the studied population resides in Mexico City at a higher latitude and pollution than many other cities and in this context, their effects on our findings remain uncertain. Also, telomere length was measured by qPCR instead quantitative fluorescence in situ hybridization (qFISH).

However, our findings support the implementation of screening studies in subjects over 60 years with associated risk factors, even when they do not have respiratory symptoms. Since emphysema has a long 
evolution before produce symptoms, it would be clinically relevant to detect the disease when lung destruction is limited and smoking cessation and other programs may prevent the progressive functional impairment.

In summary, this study reveals that a small but significant percentage of older, respiratory asymptomatic individuals present emphysematous lesions that may be diagnosed earlier mainly if they have a history of smoking and a family history of lung diseases.

\section{Declarations}

Ethical approval: study was approved by Research and Ethic Committees of our Institute (C39-14)

Consent for publication: we do not have any problem with the publication, nor statement regarding data and material availability

Conflict of interest statement: All authors declare no potential conflicts of interest.

Funding: This study was supported by Secretaría de Educación, Ciencia, Tecnología e Innovación de la Ciudad de Mexico. Grant: SECITI/115/2017.

Informed consent: signed informed consent letter was obtained from all participants

\section{Authors' contributions:}

Literature search: IBR, APL, DCP

Data collection: APL, DCP, MM

Study design: IBR, MS

Analysis of data RF, IH, DMB, MM

Manuscript preparation: IBR, APL

Review of manuscript: MS

\section{References}

1. Janssens JP, Pache JC, Nicod LP. Physiological changes in respiratory function associated with ageing. Eur Respir J. 1999; 13: 197-205.

2. Silva M, Milanese G, Sverzellati N. Interstitial lung abnormalities: prognostic stratification of subtle radiological findings. Curr Opin Pulm Med. 2018; 24: 432-439.

3. Fukuchi $Y$. The aging lung and chronic obstructive pulmonary disease: similarity and difference. Proc Am Thorac Soc. 2009; 6: 570-2. 
4. Selman M, Martinez FJ, Pardo A. Why an aging smoker lung develops IPF and not COPD? Am J Respir Crit Care Med. 2019; 199: 279-285.

5. Hazari YM, Bashir A, Habib M, Bashir S, Habib H, Qasim MA, Shah NN, Haq E, Teckman J, Fazili KM. Alpha-1-antitrypsin deficiency: Genetic variations, clinical manifestations and therapeutic interventions. Mutat Res. 2017; 773: 14-25.

6. Birch J, Anderson RK, Correia-Melo C, Jurk D, Hewitt G, Marques FM, Green NJ, Moisey E, Birrell MA, Belvisi MG, Black F, Taylor JJ, Fisher AJ, De Soyza A, Passos JF. DNA damage response at telomeres contributes to lung aging and chronic obstructive pulmonary disease. Am J Physiol Lung Cell Mol Physiol. 2015; 309: L1124-37.

7. Kureya Y, Kanazawa H, ljiri N, Tochino Y, Watanabe T, Asai K, Hirata K. Down-regulation of soluble aklotho is associated with reduction in serum irisin levels in chronic obstructive pulmonary disease. Lung. 2016; 194: 345-51.

8. Menezes AM, Perez-Padilla R, Jardim JR, Muiño A, Lopez MV, Valdivia G, Montes de Oca M, Talamo C, Hallal PC, Victora CG; PLATINO Team. Chronic obstructive pulmonary disease in five Latin American cities (the PLATINO study): a prevalence study. Lancet. 2005; 366: 1875-81.

9. Liu Z, Kuo PL, Horvath S, Crimmins E, Ferrucci L, Levine M. A new aging measure captures morbidity and mortality risk across diverse subpopulations from NHANES IV: A cohort study. PLoS Med. 2018; 15: e1002718.

10. Liu Z, Kuo PL, Horvath S, Crimmins E, Ferrucci L, Levine M. Correction: A new aging measure captures morbidity and mortality risk across diverse subpopulations from NHANES IV: A cohort study. PLoS Med. 2019; 16: e1002760.

11. Cawthon RM. Telomere measurement by quantitative PCR. Nucleic Acids Res. 2002; 30: e47.

12. Kureya Y, Kanazawa H, ljiri N, Tochino Y, Watanabe T, Asai K, Hirata K. Down-Regulation of Soluble aKlotho is Associated with Reduction in Serum Irisin Levels in Chronic Obstructive Pulmonary Disease. Lung. 2016; 194:345-351.

13. Thurlbeck WM, Müller NL. Emphysema: definition, imaging, and quantification. AJR Am J Roentgenol. 1994; 163: 1017-1025.

14. Torres-Durán M, Lopez-Campos JL, Barrecheguren M, Miravitlles M, Martinez-Delgado B, Castillo S, Escribano A, Baloira A, Navarro-Garcia MM, Pellicer D, Bañuls L, Magallón M, Casas F, Dasí F. Alpha-1 antitrypsin deficiency: outstanding questions and future directions. Orphanet J Rare Dis. 2018; 13 : 114.

15. Stanley SE, Merck SJ, Armanios M. Telomerase and the Genetics of Emphysema Susceptibility. Implications for Pathogenesis Paradigms and Patient Care. Ann Am Thorac Soc. 2016; Suppl 5: S447-S451.

16. Mannino DM, Buist AS. Global burden of COPD: risk factors, prevalence, and future trends. Lancet. 2007; 370: 765-73.

17. Alcaide AB, Sanchez-Salcedo P, Bastarrika G. Clinical features of smokers with radiological emphysema but without airway limitation. Chest. 2017; 151: 358-365. 
18. De Torres JP, Bastarrika G, Winsivesky JP, Alcaide AB, Campo A, Seijo LM, Pueyo JC, Villanueva A, Lozano MD, Montes U, Montuenga L, Zulueta JJ. Assessing the relationship between lung cancer risk and emphysema detected on low-dose CT of the Chest. Chest. 2007; 132: 1932-1938.

19. Yang Y, Mao J, Ye Z, Li J, Zhao H, Liu Y. Risk factors of chronic obstructive pulmonary disease among adults in Chinese mainland: A systematic review and meta-analysis. Respir Med. 2017; 131: 158-165.

20. Hersh CP, Hokanson JE, Lynch DA, Washko GR, Make BJ, Crapo JD, Silverman EK; COPDGene Investigators. Family history is a risk factor for COPD. Chest. 2011; 140: 343-350.

\section{Figures}
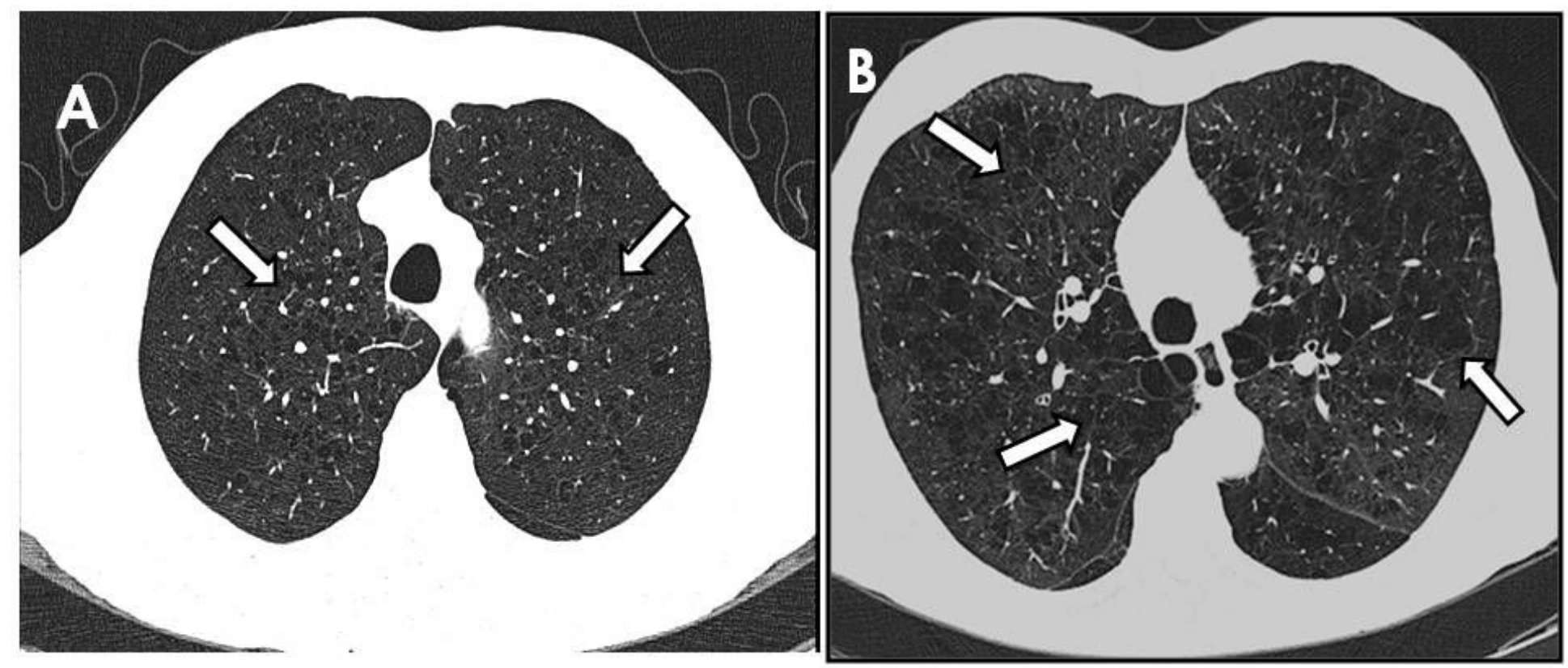

Figure 1

\section{Figure 1}

High resolution computed tomography of two different respiratory asymptomatic individuals with emphysematous lesions (arrows). 

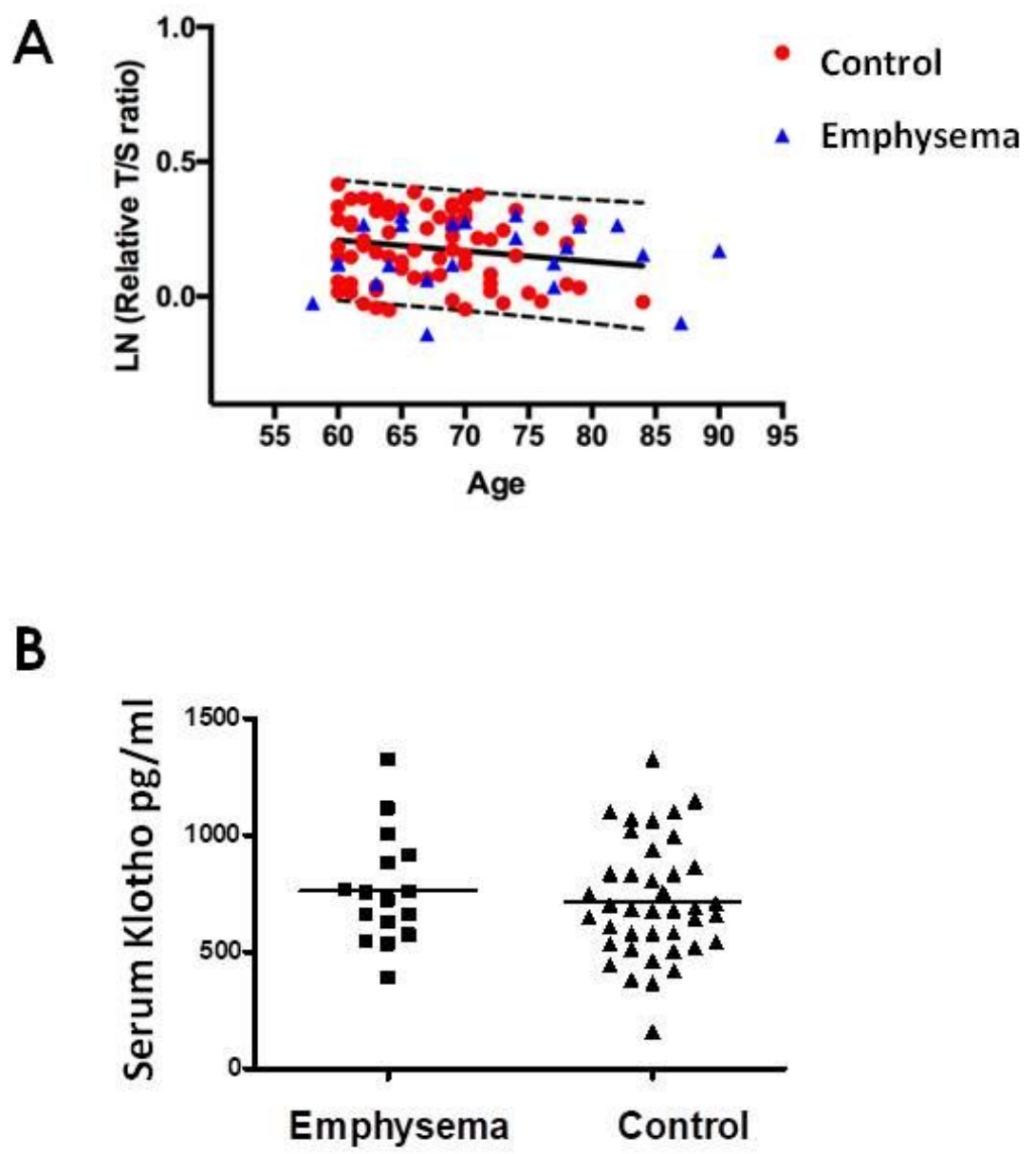

\section{Figure 2}

\section{Figure 2}

[A] Linear regression analysis of telomere length and age in individuals with emphysema and controls. Telomere length measured by qPCR from control samples (red circles, $n=83$ ) and subject with emphysema (blue triangles, $n=27$ ) was plotted relative to age. The area between the lines delineates the 10th to 90th percentile predicted bands. LN: natural logarithm of T/S ratio. [B] Serum levels of Klotho in subjects with pulmonary emphysema and controls. 


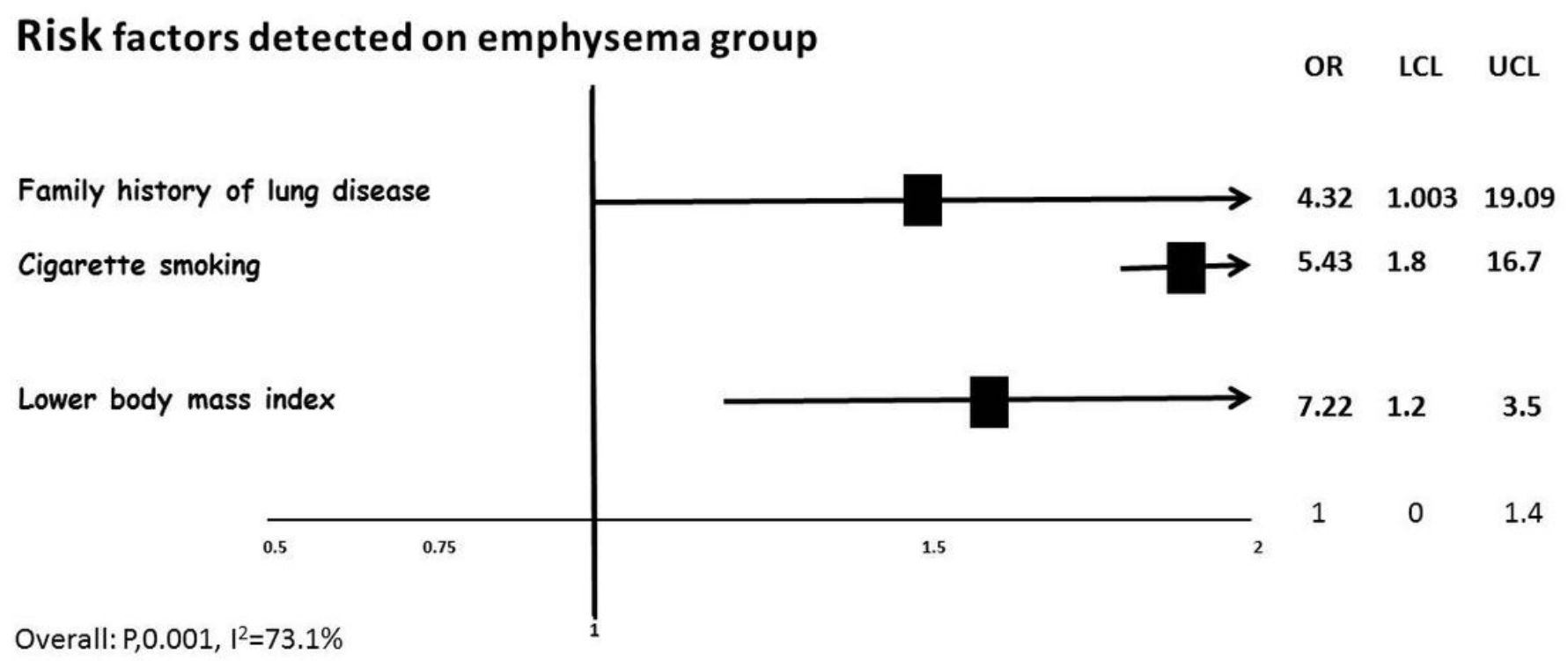

Figure 3

\section{Figure 3}

Risk factors for aging associated with pulmonary emphysema. 